\title{
Construction of an Economic Model for Prospective Forest Products Manufacturing Facilities
}

\author{
J. William Griffin, ${ }^{\mathrm{a}, *}$ R. Daniel Seale, ${ }^{\mathrm{a}, *}$ Frank C. Owens, ${ }^{\mathrm{a}}$ and Laura A. Grace ${ }^{\mathrm{b}}$ \\ In recent years, the capital investment amounts flowing into the forest \\ products industry in the southeastern United States have been unequal \\ from state to state. Reasons for this have been informally hypothesized, \\ but the topic has not been researched in depth. An economic model was \\ tested that will aid relevant stakeholders in addressing this problem. The \\ model utilizes a combination of county-level and state-level data related to \\ lumber manufacturing and a linear programming solver to produce \\ estimates of variable costs for a mill built in any Southeastern county. The \\ variable costs considered by the program include raw materials, labor, \\ electricity, and transportation costs (which are paid by the customer). \\ Future versions of the model will consider non-financial metrics such as \\ timber supply, socioeconomic statistics, and competition for timber- \\ consuming facilities. This model could be exceptionally useful to those \\ involved in industry recruitment efforts, as it provides them with an \\ objective method for evaluating counties in both their state and competing \\ states.
}

Keywords: Forest products manufacturing; Facility location; Marketing; Comparative advantage; Southern yellow pine lumber

Contact information: a: Department of Sustainable Bioproducts, Mississippi State University, 201 Locksley Way, Starkville, MS 39759, USA, (662) 325-2116; b: Department of Forestry (Retired), Mississippi State University, Box 9681, Mississippi State, MS 39762, USA, (662) 325-2949;

*Corresponding authors:jwg286@msstate.edu; rds9@msstate.edu

\section{INTRODUCTION}

The forest products manufacturing industry is larger and more important than those unfamiliar with it often assume. Lumber, panel, paper, and pellet production facilities are often the only major economic contributor for a localized rural area, making them crucial to rural economies. For example, when Georgia Pacific announced that it would halt production and lay off 650 employees at a paper mill in Bogalusa, Louisiana, in January 2019, economists estimated that for every direct job lost by a mill employee, as many as 0.35 indirect jobs were lost in the surrounding community (Fannin and Tanger 2019). Undoubtedly, supporting the industries making such a profound impact on local communities is an important task for both state-level and local-level stakeholders. Perhaps equally important is the task of industry recruitment.

Since 2017, the top 10 producers of softwood lumber in the United States have increased their production capacity by 3.4 billion board feet. Partially thanks to these expansions, these producers now account for $53 \%$ of the softwood lumber produced in the United States - over 22 billion board feet (Lang 2019). If these producers consume 4 tons of logs per 1000 board feet (MBF) of lumber produced, this is equivalent to a 13.6-millionton increase in the annual demand for softwood saw timber nationwide, assuming that they will produce at full capacity. Other sectors of the forest products industry have seen similar 
growth. Paper and cardboard mills have announced capacity expansions and equipment upgrades, and greenfield projects are also ongoing in the wood pellet industry at the time of this research (Voegele 2019). While no state being considered has been completely devoid of investments, a preliminary study of recent forest products industry investments indicated that some states have received disproportionately high levels of investment. While this should be expected to a certain extent, conventional wisdom suggests that, given the general compositions of these states, investment levels would maintain a more even distribution. Figure 1 shows amounts of forest industry capital investments since July 2014. Note Alabama's and Georgia's levels of investment compared to their surrounding states.

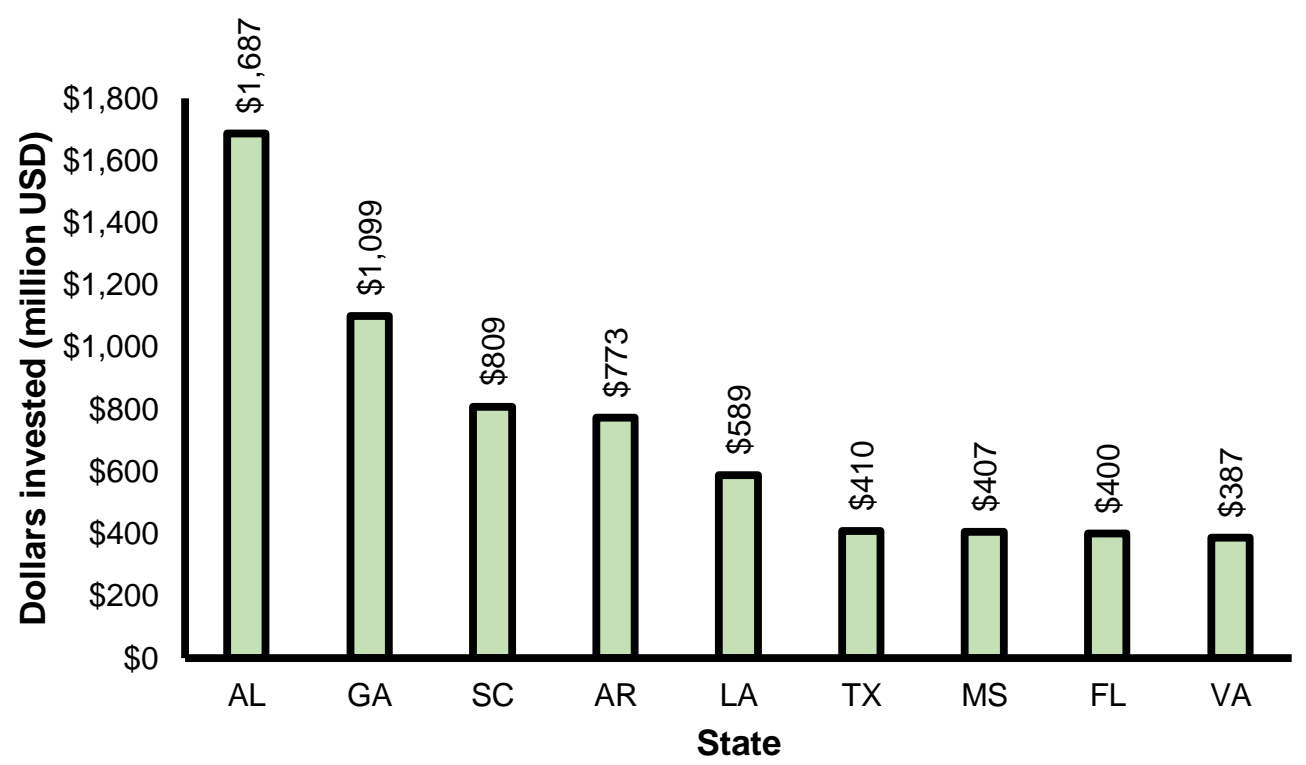

Fig. 1. Estimated levels of forest products manufacturing industry capital investments for Southeastern states since July 2014

This study examined an economic model that can objectively evaluate a given county's ability to support forest products industrial growth compared to competing counties. This model is currently in the early stages of beta testing. Once complete, it will greatly aid both current and prospective forest industry stakeholders in the evaluation of counties for new southern yellow pine (SYP) (Pinus spp.) lumber mills. State-level and county-level data relevant to lumber production were collected for the vast majority of counties in Texas, Arkansas, Louisiana, Mississippi, Tennessee, Alabama, Georgia, Florida, South Carolina, North Carolina, and Virginia. The instances where data were not collected for a county involved cases where the data were not provided by an original source.

\section{Review of Literature}

Economic models for forest industry facility location

Because investments by the industry are data-driven, researchers have historically used various types of economic models and data to identify regions of a study area that may contain the elements needed for a successful facility. Hagadone and Grala (2012) used a Poisson regression to identify clusters of forest products industry players in Mississippi and further relate these clusters to the presence, absence, or level of relevant variables. 
They found that forest products industry manufacturers in Mississippi tended to develop in clusters and that the areas where these clusters occurred contained resources that made them more competitive in the marketplace for their final product.

Sun and Zhang (2001) utilized a conditional logit model (CLM) and a time-series cross-section model (TSCS) to investigate state-level investment decisions made by forest products industry participants. The models utilized data describing the populations, economies, policies, and forests of nine southeastern states and attempted to decipher which factors influenced forest products industry investments. The results indicated that personal income per capita and raw material availability had positive influences on industry recruitment, while population density, tax rates, and energy costs had negative influences. Holley (1970) used a regional programming analysis to investigate the regional differences in production costs for the lumber and plywood industries in the United States. The results of his analysis showed that, at the time, producers located in the southeastern United States held a distinct advantage over other regions of the country because of comparatively lower transportation costs, lower logging costs, and (in the case of plywood) lower labor costs.

While the above-described studies are useful, the results are somewhat nonspecific. The model presented herein will explicitly show the financial and non-financial tradeoffs that would be incurred when a facility is built in one county versus another. This is a feature that appears to be unique to this model when compared to other publicized economic models for facility location in the forest products industry.

\section{Use of linear programming in resource allocation and forestry}

According to Anderson et al. (1991), "linear programming is a problem-solving approach that has been developed to help managers make decisions." The methodology has been widely adopted and used in a variety of industries for decades. The goal of both the simplest and most complex linear programming problem is to maximize or minimize some variable (e.g., profits or costs) according to a set of linear mathematical constraints that usually represent fixed amounts of resources. Linear programming has been a successful tool for modeling plywood mills, sawmills, forestry field operations, and various other resource-related issues in the forest industry (Field 1977).

Gautier et al. (2000) developed a linear programming model to aid Quebec Ministry of Natural Resources (MNR) officials in their understanding of the wood fiber markets in the province. Though the wood fiber market in Quebec operates freely, it was expected that this model could help all parties involved in the wood fiber trade better understand the components of the market. Based on supply-side and demand-side data collected by the MNR, the research team was able to model how fiber prices reacted in various scenarios wherein supply and demand levels were artificially changed.

Though the supply chain components differed greatly from those in the present research, Abel (1973) showed that linear programming was useful for locational planning in the forest products industry in New Zealand. A local wood processing firm wanted to know if moving a processing unit from one site to another would further minimize transportation costs. Abel's model showed that the company's existing distribution of supply chain components was already minimizing transportation costs when compared to the newly proposed arrangement. In the present model, a modified Mathematical Programming System Extended (MPSX) linear programming solver determined where to allocate shipments of lumber from the sawmill site based on lumber demand and shipping costs. 


\section{Indexing of costs}

Often, economists are interested in determining how the prices of goods fluctuate over time. The consumer price index (CPI) is the most widely known example of a system that was developed to measure year-to-year change for American consumers, but others exist as well. According to Boskin et al. (1998), the most common method for calculating price indices is the Laspeyres index formula, which is calculated according to Eq. 1,

$$
\left(\left(\sum P_{1} \times Q_{0}\right) /\left(\sum P_{0} \times Q_{0}\right)\right) \times 100
$$

where $P_{0}$ is the price in the base year, $P_{1}$ is the price in the second year in question, and $Q_{0}$ is the quantity of goods in the base year.

In the present model, a modified Laspeyres index approach was utilized to appropriately inflate or deflate the major costs that are incurred at a pro forma mill to better reflect those that may be incurred at the site that is being evaluated. The pro forma mill /mill site can be an existing mill within the company or a projected site where the company has estimated potential operating costs. This pro forma mill is used as a base from which the prospective mill's costs are estimated using the above-referenced index. Note that quantities purchased are fixed among the pro forma mill site and the mill site being analyzed, so that component was not included in this modified indexing formula. The modified indexing formula was calculated according to Eq. 2,

$$
C_{1} / C_{0}
$$

where $C_{1}$ is the per-unit cost of a component (e.g., raw material) at the mill site being evaluated and $C_{0}$ is the per-unit cost at the pro forma mill.

\section{Comparative advantage}

While much of classical economic theory assumes a perfectly competitive market, Hunt and Morgan (1995) suggest that the comparative advantage theory of competition is superior and that it more closely replicates what occurs in markets nationwide. Essential premises of comparative advantage theory that differ from the neoclassical theory are that firms operate in a world where demand is heterogeneous, that resources are both heterogeneous and imperfectly mobile, and that competition is not simply a function of quantities or levels (Hunt and Morgan 1995). In summary, the constant fluctuations and competitive shifts of the United States economy are far more adequately described by the theory of comparative advantage.

In the present economic model, the chief interest is to highlight the attributes of states that are better for lumber mills when compared with neighboring states, which thereby give the state a competitive advantage over neighboring states. For example, at present, the state of supply and demand in Mississippi timber markets is extremely imbalanced, with supply greatly exceeding demand (Measells 2018). This imbalance has led to comparatively lower timber prices state-to-state, which should be an attractive feature to any forest product manufacturer interested in locating a new facility, as it ensures that timber consumers will have low competition levels and an abundant supply of raw materials for the future.

$\mathrm{Yu}$ et al. (2008) utilized a normalized revealed comparative advantage index to evaluate whether choice agricultural products of Hawaii had lost, maintained, or increased their competitiveness versus the same products produced by the contiguous 48 states of the United States. While comparative advantage figures are not directly calculated in the present model, as by Yu et al. (2008), the premise remains the same. Where Yu et al. (2008) 
attempted to show which agricultural products of Hawaii were competitive in the marketplace, the present model will help users define which attributes of certain counties make them more competitive for sawmills.

\section{EXPERIMENTAL}

\section{Materials}

Delivered timber prices

Because log costs typically compose over half of the operating expenses of a typical sawmill (Spelter et al. 2009; Clark 2016), it is pivotal that a model of this nature contains accurate data concerning raw material costs. TimberMart-South is a leading source for reliable timber price reporting in the southeastern United States, and 2018 delivered timber prices were obtained for the model for all major timber types (TimberMart-South 2019). There are two TimberMart-South zones within each state by which prices are summarized. Because prices are available for all major products in the Southeast, this pricing data could also be useful for evaluating sites for facilities that produce other forest products that require different classes of raw materials (e.g., hardwood sawmills, oriented strand board mills, and pellet mills).

\section{Lumber demand and housing starts}

The demand for a manufacturer's product is a critical piece of information that those in the business of facility location are often tasked with estimating. In general, customers of sawmills pay the shipping costs for the products. Thus, if a competitor producing a similar product is closer to the point of demand than the new facility, the new mill will likely not be competitive. For a private company intending to build a new facility, demand figures are probably known with some degree of certainty based on its current order volume. However, established average order volumes for locations within a potential shipping region were unavailable, so another means of estimating demand was needed.

Single-family and multi-family housing starts for 2018 were obtained for 381 metropolitan areas of the United States from the National Association of Home Builders (NAHB) to estimate lumber demand throughout the United States (NAHB 2019). Some data points in the NAHB dataset listed several cities for a single housing start number. In these cases, the most prominent city was chosen for the estimation of transportation costs, which is described below.

To estimate the lumber demand for each area, the housing start estimate was multiplied by the average amount of lumber necessary to build a house or multi-family unit, as derived by the American Plywood Association (APA) (McKeever and Elling 2015). According to APA, in 2012, a single-family unit required 13,033 board feet of lumber, and a multi-family unit required 4,570 board feet of lumber. For the model, it was assumed that an equal proportion of units are built using lumber across all demand points, which is unlikely. Additionally, the demand figure did not account for lumber used in the remodeling of homes or businesses. Regardless, the derived numbers served as a good indicator of relative levels of lumber demand throughout the United States.

\section{Transportation costs}

The Bureau of Transportation Statistics estimates that the final demand for transportation accounted for $9 \%$ of the United States gross domestic product (BTS 2018). 
This figure shows the importance and costs of transportation for all types of industries, including the forest products industry. Accurate mileages from prospective mill counties to the end-use product markets discussed above are important. These mileages were determined by integrating the Bing Maps API (2019, Microsoft Corporation, Redmond, WA, USA) into Microsoft Excel (2016, Microsoft Corporation, Redmond, WA, USA) spreadsheet software and calculating mileages between all possible mill source locations in the Southeast and the above-described end-product market locations (Bing Maps 2019). For each county, it was assumed that the mill site would be in the county seat.

The table containing all source-destination combinations was created using the programming language $\mathrm{R}$ and was then converted to a spreadsheet workbook, where the mileage calculations were completed in additional columns. There were more than 420,000 source-destination pairs in the spreadsheet. When a potential mill site was selected, transportation costs per unit were calculated according to Eq. 3,

$$
(S R \times O W M) / M B F_{\mathrm{TL}}
$$

where $M B F_{\mathrm{TL}}$ is the average amount of board footage that can be shipped per truckload, $S R$ is the shipping rate per mile, and $O W M$ is the one-way mileage between the county seat of the county being analyzed and a market for lumber.

\section{Electricity costs}

The United States Energy Information Administration (EIA) is a well-trusted source of information related to energy in the United States (EIA 2019). The Annual Electric Power Industry Report includes several datasets that report on both the sales and purchases of electricity in the United States. A dataset that reported both total revenue and gigawatt-hours sold by utility providers to industrial customers and a dataset listing the counties serviced by each utility provider were used to obtain an average industrial rate for each provider. Then, using the calculated rate for each utility and the dataset that reported which counties were served by every utility, it was possible to calculate the average industrial rate for every county.

\section{Labor costs}

The Quarterly Census of Employment and Wages program of the Bureau of Labor Statistics (BLS) collects data related to wages for multiple industries (BLS 2019). Average weekly wages for the first quarter of 2019 for all manufacturing industries were used to compute an estimate of labor costs for the prospective mill. While the BLS does collect wage data specific to sawmills, it was decided to use generic manufacturing wages, as these figures seemed to more accurately reflect the true cost of labor in a given county. Additionally, the sawmill wage data were only available for select counties and the state level, which did not seem to adequately reflect the differences in labor costs from county to county.

Note: The following three types of data are not yet fully incorporated into the model, but they are intended to be fully incorporated before the model is released for public use.

\section{Timber supply and timber depletion rates}

Timber supply is an important metric for companies to consider when locating a forest products manufacturing facility, as proper raw material supply is important to the long-term viability of a plant. Additionally, where timber is in short supply, its price will likely be greater than in an area where timber is plentiful. The Forest Inventory and 
Analysis (FIA) Program is an annual survey of the forests in the United States (FIA 2019). Plots that have been permanently established throughout the country are revisited, and data is collected, allowing users to monitor forest growth, removal, and status.

These data are free to the public, and the flexible nature of the FIA database query application allows the user to view the available data in various ways. Although the data collected and analyzed by the program is not highly accurate at the micro-scale, it is the only such data source in existence for the forests of the United States and thus provides a relative measure of timber supply for the short and long terms. Because FIA data is collected by state agencies, the years in which the datasets were updated are not consistent from state to state. Regardless, the data adequately show regional changes in timber supply.

Because sawmills rarely buy timber from only one county, the amount of timber available to a sawmill at a given site was considered to be the amount of timber in that county and every county adjacent to the site. This was accomplished by using the county adjacency file provided by the United States Census Bureau (U.S. Census Bureau 2018). The county adjacency file was modified in a spreadsheet such that the second column contained every county adjacent to the source county (listed in the first column). The VLOOKUP function was used to quickly find the values for all of the source county's adjacent counties. Using a pivot table on this sheet, the "wood basket" for each county could be evaluated. Notably, in many cases, a mill may purchase timber from far beyond each county it is adjacent to. This distance depends on the shapes and orientations of the forests within an affordable distance from the mill and the amount of timber that a given mill will purchase. However, it was considered preferable to assume this simplified model, compared to making a more detailed and extreme assumption.

In addition to volume estimates, net growth and removal estimates for every county's aforementioned "wood basket" were also collected. The sum of the net growths in a county and adjacent counties divided by the sum of the removals for a county and its adjacent counties yields a ratio that is commonly called a "growth-to-drain ratio." In a county with an estimated growth-to-drain ratio of 2.0, two tons of timber is grown for every ton removed. In a county with a growth-to-drain ratio of 1.0, one ton of timber is grown for every ton removed. In a county with a growth-to-drain ratio less than 1, the reciprocal of the value should be calculated to obtain the removal-to-growth ratio, which is of comparable scale to a positive growth to drain ratio. For instance, if a growth-to-drain ratio is calculated as 0.75 , it means that 1.33 (i.e., $1 \div 0.75$ ) tons of timber is removed for every ton grown.

\section{County-level socioeconomic statistics}

Statistics regarding the labor force and overall economy of a county are also of interest to any organization seeking to build a new facility. The Atlas of Rural and SmallTown America dataset, created by the United States Department of Agriculture's Economic Research Service (ERS), was obtained to aid in showing regional differences in the United States workforce and population dynamics (ERS 2019). The dataset is summarized by county, which was a slight limitation because many mills hire workers outside of the county in which they build, but it sufficed for this analysis. Some important metrics in the dataset, which could be of interest to potential sawmill operators, are the 2010 population as recorded in the 2010 census, a 2017 population estimate, and the 2017 unemployment rates. 


\section{Competing timber-consuming industries}

As is true in any marketplace for goods and services, the relationship between supply and demand greatly affects the price of that good or service. Therefore, the timber demand from competing mills in a county's "wood basket" were included via wood consumption data provided by the Wood Demand Report of the University of Georgia (UGA) Harley Langdale, Jr. Center for Forest Business (UGA 2019). The version of the dataset used is accurate up to the end of the third quarter of 2018.

Demand from sawmills, plywood mills, and pole mills was considered; for, in theory, these three types of mills could all compete for the same log if supply is constrained. A similar methodology was used to develop this data as was used for the timber supply and growth-to-drain ratios: The competing timber demand was assumed to be the sum of all pine plywood, pine saw timber, and pole demands for the county in question and all adjacent counties.

\section{Methods}

\section{Data integration}

All of the above-referenced data were collected through the publishing entities' websites or by direct contact with the publishing entities. Once each dataset was properly formatted using the spreadsheet software, they were downloaded into the Microsoft Access (2003, Microsoft Corporation, Redmond, WA, USA) database software using a query, the database software's table data upload function, or a combination of these two methods. Microsoft Access forms within this database serve as the user interface for the model.

\section{Linear programming solver}

The modified MPSX linear programming solver used to estimate a site's lumber shipment allocation mix and produce cost estimates was developed by in the Department of Sustainable Bioproducts at Mississippi State University. The solver requires a very specifically formatted text file (Modified MPSX for 16-character row and column names) in order to run correctly and produce a solution. This text file is generated by the Access database through a succession of queries that recall the data associated with the county being analyzed, the pro forma data for the prospective mill, and other user input data (e.g., trucking rates).

Once the optimal solution has been calculated by the solver, it generates the solution file showing the optimal values for each item and an estimate of mill profit (e.g., the optimal amount of lumber to ship from mill site A to Memphis, TN.)

\section{RESULTS AND DISCUSSION}

The application and distinctiveness of this research are best exemplified through a condensed depiction of an analysis conducted using the model. For this example, it was assumed that the model user wishes to evaluate the profitability of a sawmill in Smith County, Mississippi. Note that some of the numbers and results depicted in this example might not be commensurate with real-world figures. This is because the model is still in beta testing, and some forms, datasets, or queries still need to be repaired. Figure 2 shows the main menu within the user interface of the model. 


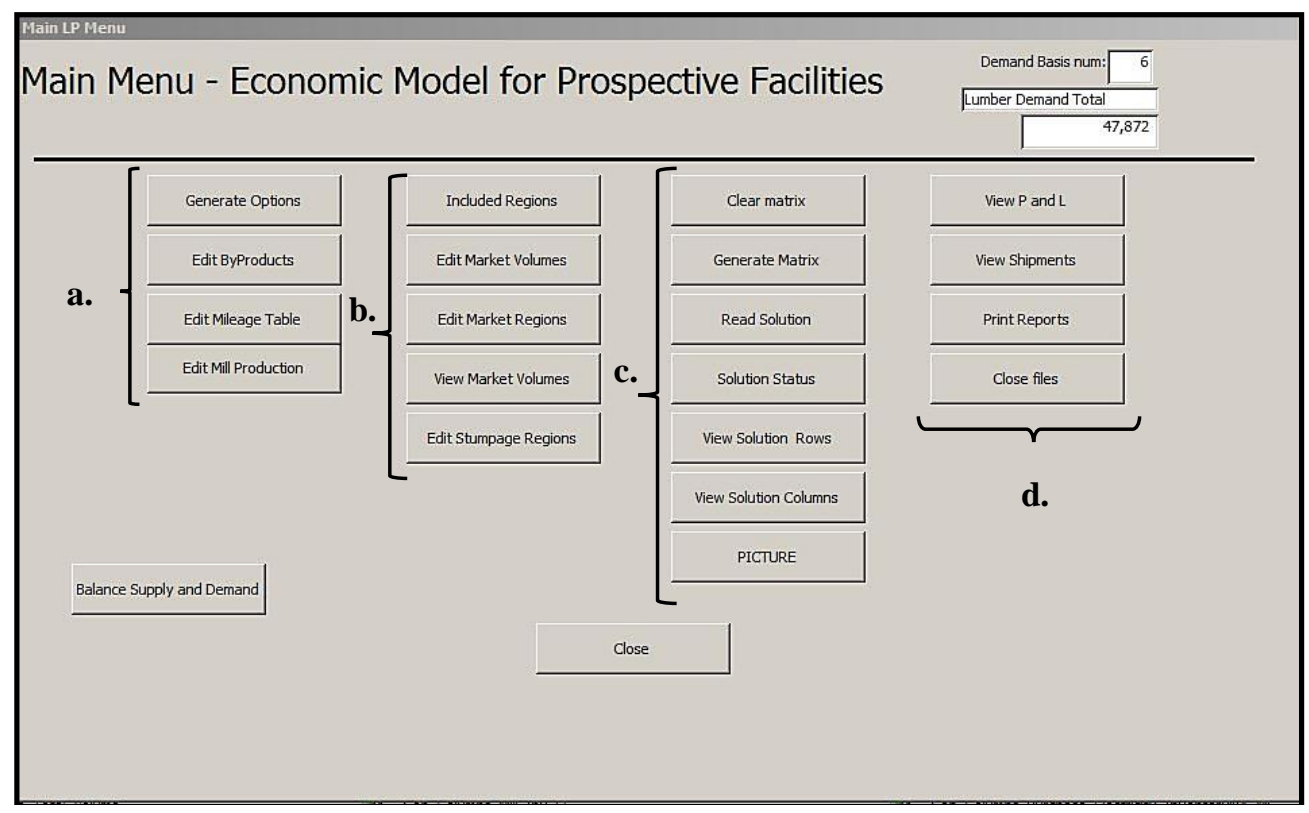

Fig. 2. The main menu of the model interface. Labels a., b., c., and d. are discussed in depth below.

The group of buttons demarcated with the bracket labeled "a." are related to the model's initial setup. The most important button in this group is the "Generate Options" button, which leads to a menu wherein the user defines many variables specific to his or her situation. The "Generate Options" interface is shown in Fig. 3.

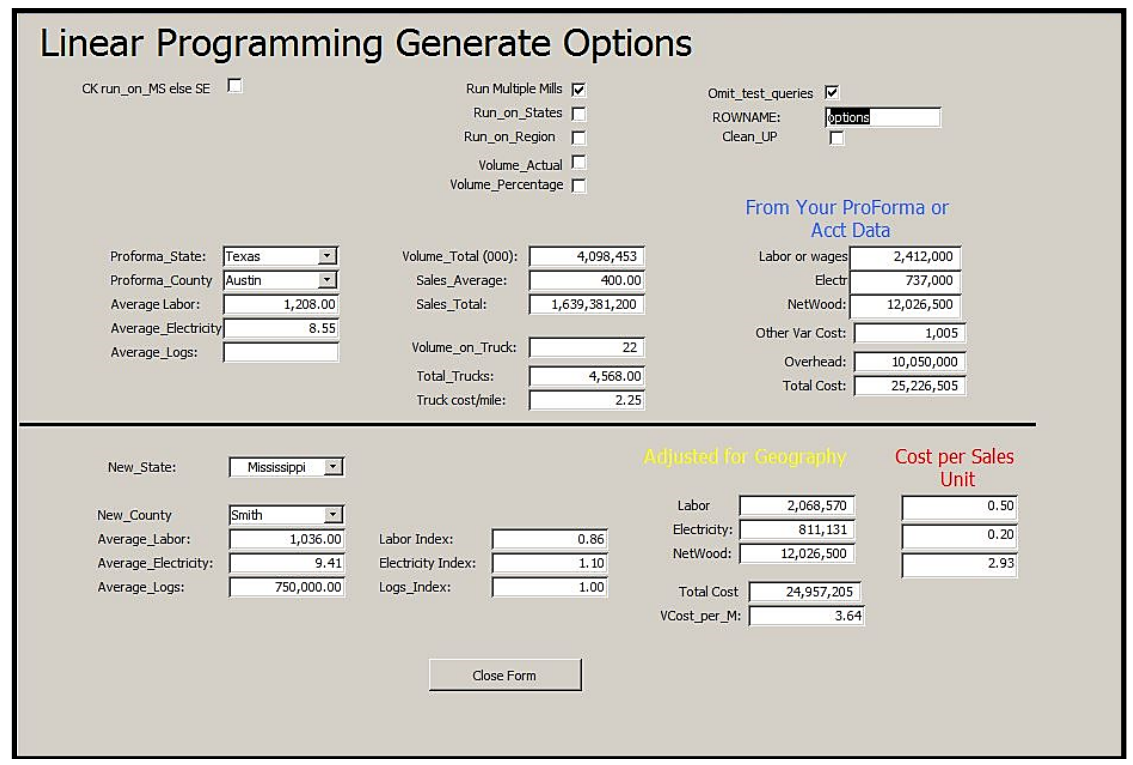

Fig. 3. Interface for "Generate Options"

The model uses Eq. 2 to index the costs incurred in the proforma county to the new county. If the user wishes to avoid using this indexing method and simply run the model to obtain the estimates, he or she could simply enter the state and county of the site being analyzed in the "Proforma_County" and "Proforma_State" dropdown lists. Other editable metrics include the sales average for lumber sold and the amount of lumber it is possible 
to ship on one truck, in MBF.

All buttons in the group demarcated with bracket "b." (Fig. 2) are important. "Included Regions," "View Market Volumes," "Edit Market Volumes," and "Edit Market Regions" are all related to viewing and modifying the lumber demand data derived using the NAHB/APA data discussed in the Experimental section. The user interface for the "Included Regions" button is shown in Fig. 4.

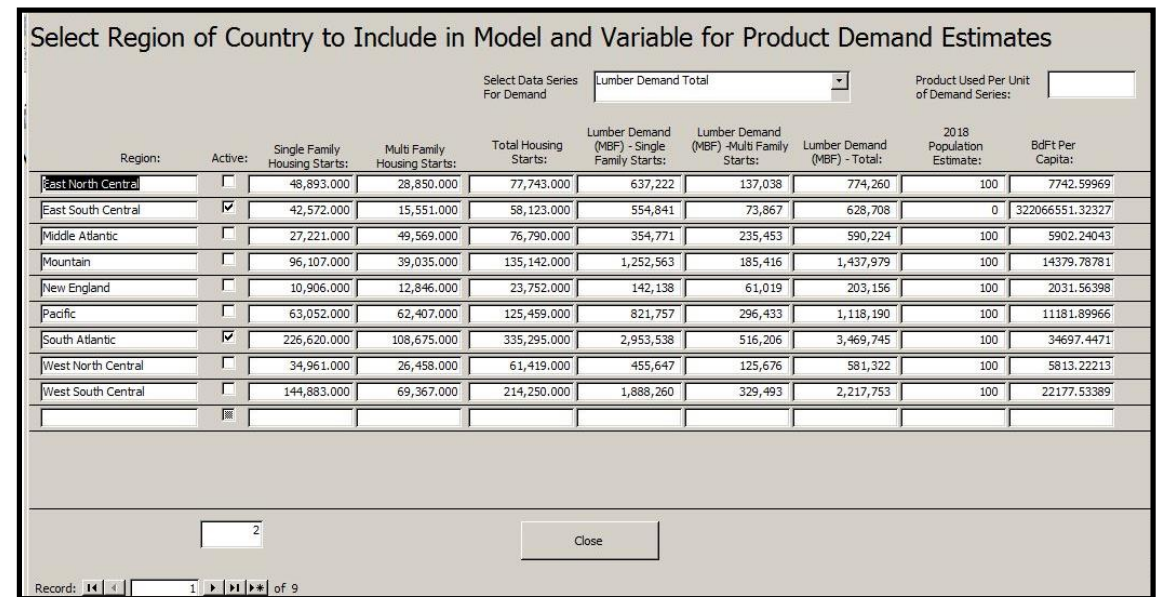

Fig. 4. Interface for "Included Regions"

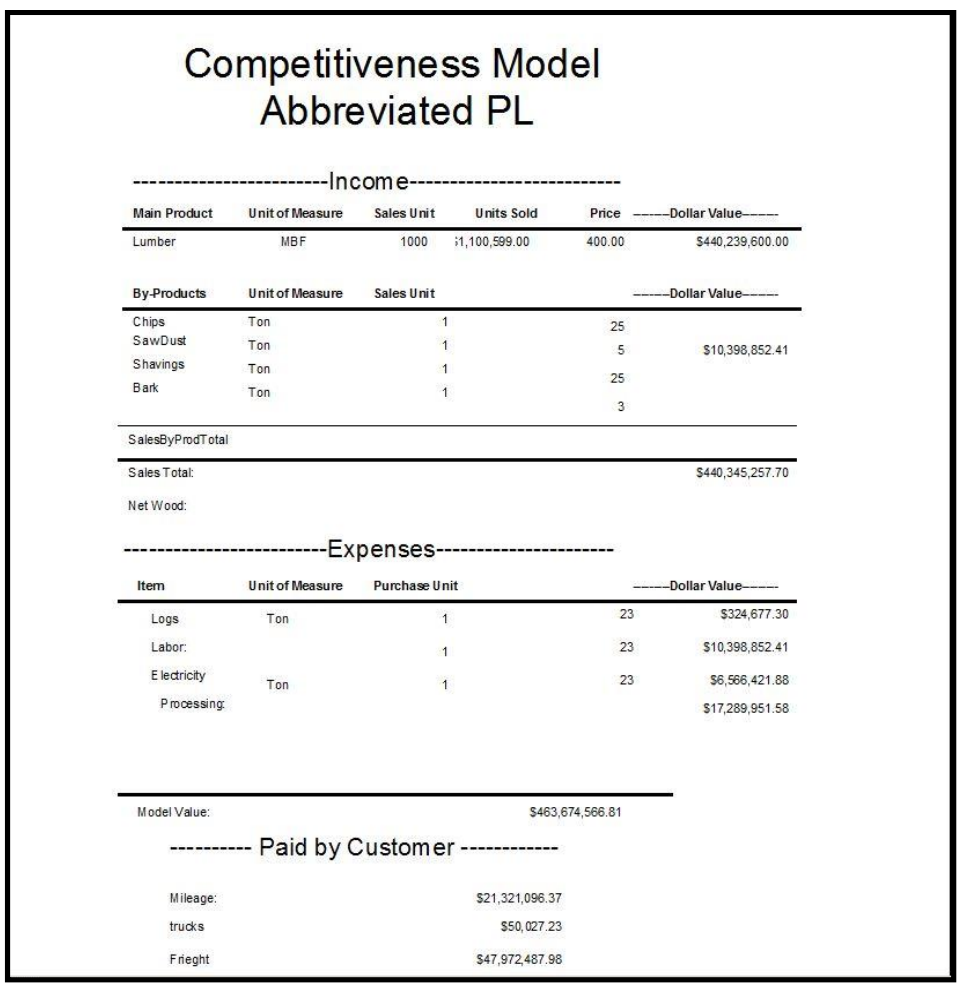

Fig. 5. Section of a profit and loss statement (P\&L) from the model

Here, the user can decide which regions of the United States (as defined by the U.S. Census Bureau) that he or she intends to ship lumber to, from the analysis county. This provides a means for the user to filter the 381 metropolitan areas that are included. Within 
this interface, the user can also select which unit of demand to use in the allocation of shipments (i.e., housing starts, lumber demand, or population). The "Edit Market Volumes" menu should be used when demand numbers not included in the model, such as figures estimated by a prospective company, are a more accurate representation of demand levels.

The three most important buttons in the "c." and "d." groupings are "Generate Matrix," "View P\&L," and "View Shipments." Clicking "Generate Matrix" runs the linear programming model and develops a solution file showing optimal shipment levels and estimates of profits and costs. Due to the complexity of this solution file, additional steps were taken to summarize the estimates in concise reports. These reports can be viewed by clicking "View P\&L" or "View Shipments." Figures 5 and 6 show examples of the reports generated by these buttons.

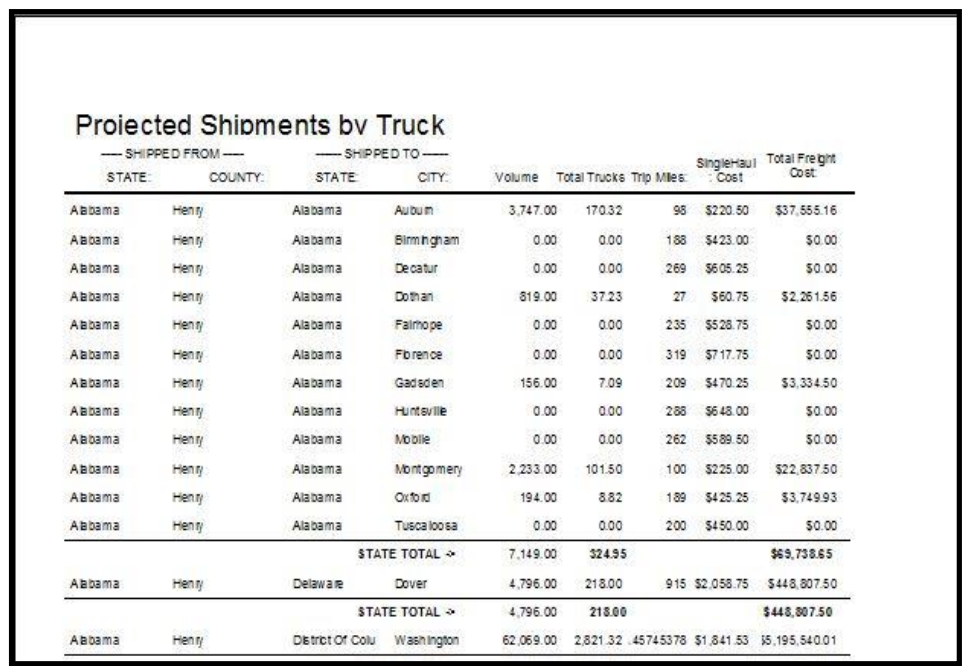

Fig. 6. Example of a shipment report produced by the model

While all other buttons and portions of the model interface are certainly important and relevant, an in-depth discussion and explanation of them is not required for the reader to understand the general functions of the model. Rather, they are briefly described in Table 1 .

Table 1. General Functions of Other Buttons in the Primary Model Interface

\begin{tabular}{|c|c|}
\hline Button Title & Function \\
\hline Balance Supply and Demand & Adjust market demand to account for mill production levels \\
\hline Edit Byproducts & Edit mill byproduct yields \\
\hline Edit Mileage Table & Change default mileages \\
\hline Edit Mill Production & Change mill production levels \\
\hline Edit Stumpage Regions & Edit raw materials costs for a county \\
\hline Clear Matrix & Delete current matrix \\
\hline Read Solution & Read solution file into the model \\
\hline Solution Status & Determine if model ran successfully \\
\hline View Solution Rows & View the solution file rows \\
\hline View Solution Columns & View the solution file columns \\
\hline PICTURE & Generate an image of the linear program \\
\hline Print Reports & Print hard copies of reports \\
\hline Close Files & Close any open files related to the model \\
\hline
\end{tabular}


A function of the model not yet discussed in this paper is its ability to optimize the shipping activities of multiple company sawmills in a single iteration. If desired, a user may add annual production volumes to all the Southeastern counties to procure results that account for the transportation advantages maintained by each sawmill in the company. This feature could be useful to company analysts that are tasked with finding the optimal location for a new sawmill relative to existing company sawmills. Early tests of this feature have been interesting and promising but do not yet merit further in-depth discussion.

\section{CONCLUSIONS}

1. Though it is undergoing beta testing, early tests showed that the model is different from most recently publicized literature related to facility location for the forest products industry. Whereas other models have used methods of analysis that produce general and inexplicit results, this model provides its users with an objective estimate of the variable costs that a sawmill would incur if located within a given county. Furthermore, the model allows the user to obtain variable cost estimates for any number of counties using the same methods and data, which is necessary for the purposes of objectivity.

2. This model will be an excellent tool for current and future stakeholders in the forest and forest products industries throughout the southern United States. Economic developers will be able to use it to demonstrate their preferred location's strengths when compared to other locations. The model will also be useful to firms that wish to quickly gather information about several different sites during their initial search for new locations to build new forest products manufacturing facilities.

\section{ACKNOWLEDGMENTS}

This work was supported by the USDA National Institute of Food and Agriculture, McIntire Stennis Project \#1015681. This publication is a contribution of the Forest and Wildlife Research Center, Mississippi State University. The authors are grateful for the support and advice provided by the following people and their respective organizations: Harrison Hood, Ph.D. (Hood Consulting), Brandon Hatchett (Metlife), William "Skip" Scaggs (North Mississippi Industrial Development Association), Anderson Thomas (Shuqualak Lumber), Hunter McShan (McShan Lumber Company), Dr. Brian Mitchell (Mississippi Forestry Commission), and Ray Beeson (Weyerhaeuser Wood Products, Bruce, MS).

\section{REFERENCES CITED}

Abel, D. B. (1973). "Linear programming and its application to the locational planning of wood-processing industries," New Zealand Journal of Forestry Science 3(2), 259269.

Anderson, D. R., Sweeney, D. J., and Williams, T. A. (1991). An Introduction to Management Science, West Publishing Company, St. Paul, MN, USA.

Bing Maps (2019). "Choose your API," Microsoft, (https://www.microsoft.com/en- 
us/maps/choose-your-bing-maps-api), Accessed 12 Aug 2019.

BLS (2019). "Quarterly census of employment and wages," Bureau of Labor Statistics, (https://www.bls.gov/cew/downloadable-data-files.htm), Accessed 15 Jan 2020.

Boskin, M. J., Dulberger, E. L., Gordon, R. J., Griliches, Z., and Jorgenson, D. W. (1998). "Consumer prices, the consumer price index, and the cost of living," Journal of Economic Perspectives 12(1), 3-26. DOI: 10.1257/jep.12.1.3

BTS (2018). "TET 2017 - Chapter 2 - Transportation's contribution to the economy," Bureau of Transportation Statistics, (https://www.bts.gov/browse-statistical-productsand-data/transportation-economic-trends/tet-2017-chapter-2), Accessed 12 Aug 2019.

Clark, J. (2016). "Return to log: How sawmills determine a log's value," Forest2Market, (https://www.forest2market.com/blog/return-to-log-how-sawmills-determine-logvalue), Accessed 27 Aug 2019.

EIA (2019). "Annual electric power industry report, form EIA-861 detailed data files," United States Department of Energy, Energy Information Administration, (https://www.eia.gov/electricity/data/eia861/), Accessed 24 Sep 2019.

ERS (2019). "Atlas of rural and small-town America," United States Department of Agriculture, Economic Research Service, (https://www.ers.usda.gov/dataproducts/atlas-of-rural-and-small-town-america/), Accessed 24 Sep 2019.

Fannin, J. M., and Tanger, S. (2019). Measuring the Economic Consequences of the Layoffs at the Georgia-Pacific Paper Mill on the Economy of the Greater Zachary Region (Staff Report 2019-28), Louisiana State University, Department of Agricultural Economics and Agribusiness, Baton Rouge, LA, USA.

FIA (2019). "Welcome to our site," United States Department of Agriculture, U.S. Forest Service, Forest Inventory \& Analysis (https://www.fia.fs.fed.us), Accessed 12 Aug 2019.

Field, D. B. (1977). "Linear programing: Out of the classroom and into the woods," Journal of Forestry 75(6), 330-334. DOI: 10.1093/jof/75.6.330

Gautier, A., Lamond, B. F., Paré, D., and Rouleau, F. (2000). "The Québec Ministry of Natural Resources uses linear programming to understand the wood-fiber market," Interfaces 30(6), 32-48. DOI: 10.1287/inte.30.6.32.11625

Hagadone, T. A., and Grala, R. K. (2012). "Business clusters in Mississippi's forest products industry," Forest Policy and Economics 20, 16-24. DOI:

10.1016/j.forpol.2012.01.011

Holley, D. L. (1970). "Location of the softwood plywood and lumber industries: A regional programming analysis," Land Economics 46(2), 127-137. DOI: $10.2307 / 3145170$

Hunt, S. D., and Morgan, R. M. (1995). "The comparative advantage theory of competition," Journal of Marketing 59(2), 1-15. DOI: 10.2307/1252069

Lang, A. (2019). "Who's who in lumber 2019 update: Top 10 U.S. lumber producers," Forisk Consulting, (https://forisk.com/blog/2019/08/02/whos-who-in-lumber-updatetop-10-u-s-lumber-producers/), Accessed 23 Aug 2019.

McKeever, D. B., and Elling, J. (2015). Wood Products and Other Building Materials Used in New Residential Construction in the United States, with Comparison to Previous Studies 2012, APA - The Engineered Wood Association, Tacoma, WA, USA.

Measells, M. (2018). "Market forces impacting timber prices," in: Neshoba County Forestry Association Meeting, Philadelphia, MS, USA.

NAHB (2019). "Housing economics," National Association of Home Builders, 
(https://www.nahb.org/research/housing-economics.aspx), Accessed 12 Aug 2019.

Spelter, H., McKeever, D., and Toth, D. (2009). Profile 2009: Softwood Sawmills in the United States and Canada (Research Paper FPL-RP-659), United States Department of Agriculture, Forest Service, Forest Products Laboratory, Madison, WI, USA. DOI: 10.2737/FPL-RP-659

Sun, C., and Zhang, D. (2001). "Forest resources, government policy, and investment location decisions of the forest products industry in the southern United States," Forest Science 47(2), 169-177.

TimberMart-South (2019). "Home," TimberMart-South, (http://www.timbermartsouth.com), Accessed 12 Aug 2019.

UGA Harley Langdale, Jr. Center for Forest Business (2019). "Wood Demand Research Program," UGA, (http://www.ugacfb.com/research/wdrp/), Accessed 3 Feb 2020.

U.S. Census Bureau (2018). “County adjacency file,” United States Census Bureau, (https://www.census.gov/programs-surveys/geography/library/reference/countyadjacency-file.html), Accessed 15 Jan 2020.

Voegele, E. (2019). "Enviva announces new contracts, plans to increase capacity," Biomass Magazine, (http://biomassmagazine.com/articles/16382/enviva-announcesnew-contracts-plans-to-increase-capacity), Accessed 3 Sep 2019.

Yu, R., Cai, J., Leung, P., and Loke, M. K. (2008). "Comparative advantage trends of selected Hawai'i agricultural products in the U.S. mainland market," Economic Issues $14,1-11$.

Article submitted: January 21, 2020; Peer review completed: March 14, 2020; Revised version received and accepted: April 2, 2020; Published: April 7, 2020.

DOI: 10.15376/biores.15.2.3874-3887 